\title{
Influence of Obstacles on the Development of Gravity Current Prior to Backdraft
}

\author{
Christian Pérez-Jiménez*, LABEIN-TECNALIA S.A.I., Bilbao, Spain \\ Georges Jan Guigay, Bjorn Karlsson and Jonas Eliasson, Iceland Fire Authority, \\ Reykjavik, Iceland \\ Andrej Horvat, Intelligent Fluid Solutions, London, UK \\ Yehuda Sinai, ANSYS UK Ltd., Sheffield, UK \\ Jean-Marc Franssen, University of Liege, Liege, Belgium
}

Received: 8 November 2006/Accepted: 22 August 2008

\begin{abstract}
The phenomenon of backdraft is closely linked to the formation of a flammable region due to the mixing process between the unburned gases accumulated in the compartment and the fresh air entering the compartment through a recently created opening. The flow of incoming fresh air is called the gravity current. Gravity current prior to backdraft has already been studied, Fleischmann (1993, Backdraft phenomena, NIST-GCR-94-646. University of California, Berkeley) and Fleischmann (1999, Numerical and experimental gravity currents related to backdrafts, Fire Safety Journal); Weng et al. (2002, Exp Fluids 33:398-404), but all simulations and experiments found in the current literature are systematically based on a perfectly regular volume, usually parallelipedic in shape, without any piece of furniture or equipment in the compartment. Yet, various obstacles are normally found in real compartments and the question is whether they affect the gravity current velocity and the level of mixing between fresh and vitiated gases. In the work reported here, gravity current prior to backdraft in compartment with obstacles is investigated by means of three-dimensional CFD numerical simulations. These simulations use as a reference case the backdraft experiment test carried out by Gojkovic (2000, Initial Backdraft. Department of Fire Safety Engineering, Lunds Tekniska Högskola Universitet, Report 3121). The Froude number, the transit time and the ignition time are obtained from the computations and compared to the tests in order to validate the model.
\end{abstract}

Keyword: gravity current, 3-D simulation, obstacles, backdraft, ignition time

\section{Nomenclature}

$B \quad$ Width of the container (m)

C Drag coefficient of the obstacle

Fr Froude number

$F \quad$ Force $(\mathrm{N})$

$g \quad$ Gravity $\left(\mathrm{m} / \mathrm{s}^{2}\right)$

$h \quad$ Height of the obstacle (m)

$h^{*} \quad$ Non-dimensional height of the gravity current

$h_{\mathrm{o}} \quad$ Height of the gravity current measured over the distance $3 L / 4$ to $L$ (m)

\footnotetext{
* Correspondence should be addressed to: Christian Pérez-Jiménez, E-mail: cperez@labein.es
} 


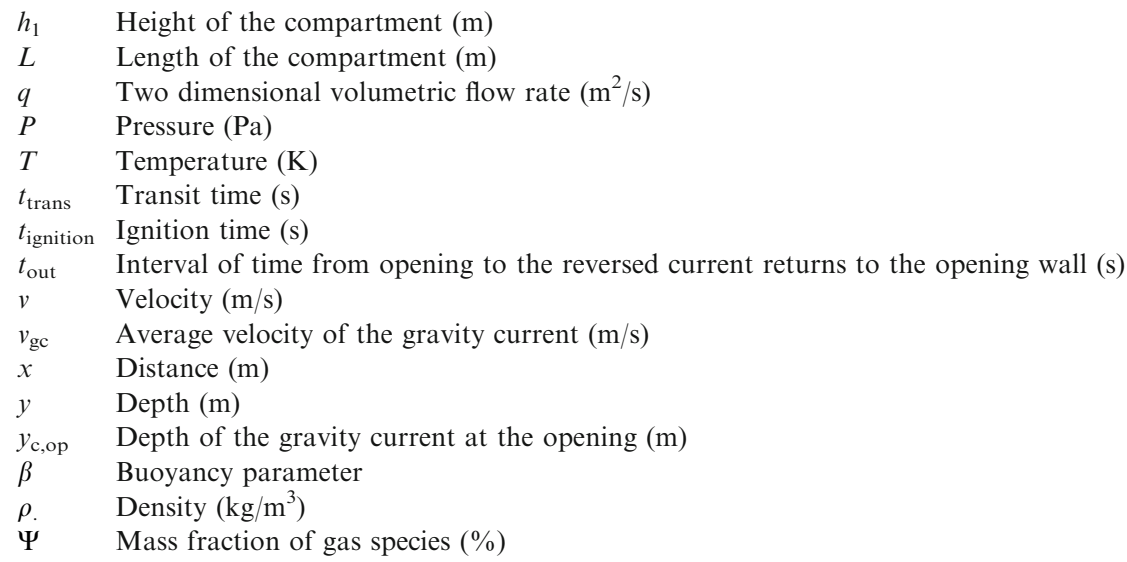

\section{Sub-script}

$\begin{array}{ll}\text { 1, } 2 & \text { Indicates a section of the gravity current } \\ \text { w } & \text { Waterfall } \\ \text { h, c } & \text { Hot, cold } \\ \text { obst } & \text { Obstacle }\end{array}$

\section{Introduction}

A gravity current is the flow of one fluid into another, which is caused by a difference in density between the fluids under the influence of gravity. This density difference may be due to differences in chemical composition or in temperature between the two fluids. There are many common examples of gravity current such as sea breeze fronts, avalanches, lock exchanges, flows following volcanic eruptions, etc.

Research work on gravity currents prior to backdraft has already been published. Fleischmann [1] conducted a series of scaled saltwater experiments using flow visualizations. Its purpose was to investigate the gravity current speed and the extent of the mixing region. The compartment $(0.3 \mathrm{~m} \times 0.15 \mathrm{~m} \times 0.15 \mathrm{~m})$ was fitted with a variety of opening geometries (full, middle slot, door and window) on one side. His work showed that, in the case of full opening, the mixing layer between incoming gravity current and the surrounding fluid gradually expands to occupy nearly the entire compartment. Furthermore, Fleischmann showed that the Froude number and the non-dimensional head height of the gravity current, $h^{*}$, are independent of the density difference ratio.

Weng [2] also conducted some analyses of saltwater gravity currents using flow visualization and digital particle image velocity. The scaled compartment $(0.6 \mathrm{~m} \times 0.2 \mathrm{~m} \times 0.3 \mathrm{~m})$ was fitted with vertical openings of various geometries (full, middle slot, door and window) combined with a ceiling opening.

However, these research works did not investigate the possible influence of obstacles in the compartment on the gravity current. In real fires, various types of furniture, equipment or other kind of obstacles are usually scattered on the floor. Such obstacles create some flow resistance that may lead to breaking of the 
gravity wave and cause an internal hydraulic jump. Such jumps would cause forced mixing that again would affect the resulting species concentrations and thus would alter the conditions for backdraft formation [11].

The purpose of the present analysis was to determine the influence of obstacles on gravity current mixing and on the ignition time using three-dimensional numerical CFD simulations. To validate the modelling approach, the experimental data of the backdraft experiment (test number 9) performed by Gojkovic [3] in a shipping container is used for comparison.

However, before being able to carry out this study, it was necessary to check the setup of the model by comparison with the results obtained in Fleischmann's scaled saltwater experiments. All this part is represented in the Annex.

Note should be made of the fact that some work has been done on simulation of the flame dynamics subsequent to ignition. A full review would be beyond the scope of this paper, but reference will be made here to work by Horvat et al. [4] on dynamic and physical simulation of the whole event, covering the gravity current, ignition, and deflagration, in the absence of obstacles.

\subsection{Experimental Setup of Gojkovic}

The experimental rig was built from a standard shipping container, measuring $5.5 \mathrm{~m} \times 2.2 \mathrm{~m} \times 2.2 \mathrm{~m}$ (length $\times$ width $\times$ height). The container was raised $0.4 \mathrm{~m}$ from the ground. The walls were insulated with glass fibre insulation and the floor was covered with concrete. The middle-slot opening covered $1 / 3$ of the container's height $(2.2 \mathrm{~m}$ wide and 0.7 high $)$ and it was closed with a hatch. See Figure 1.

The fuel used in the backdraft experiments was natural gas (98\% methane). To ignite the combustible mixture in the container, an electrically heated metal wire was placed at the end of the container as an ignition source. The wire was approximately $1.0 \mathrm{~m}$ long and vertically oriented.

\subsection{Experimental Procedure of Gojkovic' Experiments}

The experiment starts by closing the middle-slot opening and the pressure relief panel. A small ventilation hole is opened to vent the overpressure created when

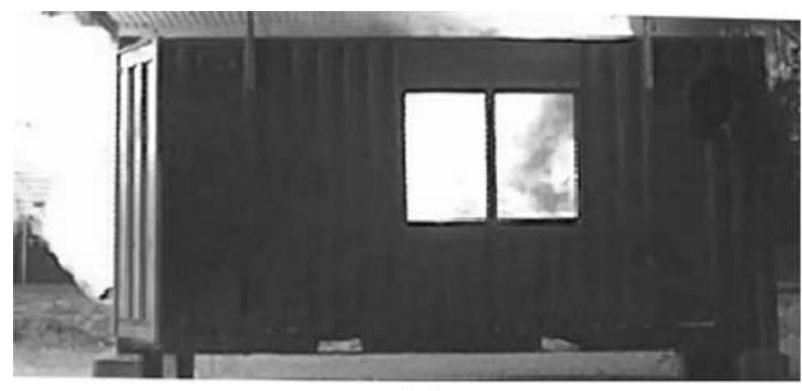

(a)

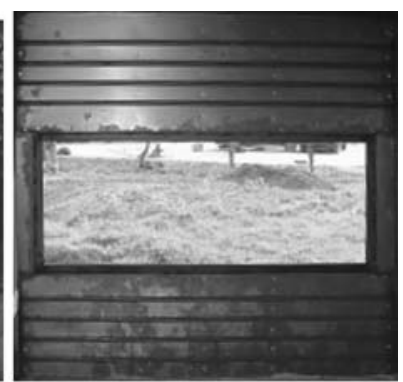

(b)

\section{Figure 1. (a) Shipping container used in backdraft experiments; (b) middle-slot opening of the container [3].}


starting the flame. The flame dies out approximately $1 \mathrm{~min}$ after the beginning of the fire. However, the natural gas is kept flowing through the burner in order to simulate the pyrolysis process where a high concentration of combustible gas is generated. After a certain time, the burner is turned off, the ignition source is turned on and the middle slot hatch is opened.

Surrounding air flows in the compartment in form of a gravity current and mixes with the natural gas and combustion products, creating a flammable region. When this flammable region reaches the ignition source, the gas mixture is ignited and the backdraft deflagration starts. The numerical simulations performed here cover the time interval between the opening of the hatch and the ignition of the flammable mixture, that is, the period during which the gravity current develops.

\section{Gravity Current Simulation: Gojkovic's Experiment}

\subsection{Geometry Arrangement}

Two gravity current scenarios were studied. Figure 2(a) shows the compartment without obstacles as tested by Gojkovic, whereas Figure 2(b) presents the compartment with obstacles. In the text, the case without obstacles is referred as FreeObstacles case and the case with obstacles is referred as Zig-Zag case.

The flammability conditions that are temperature and concentration dependent [5] are checked in a cylindrical volume of $1.0 \mathrm{~m} \times 0.1 \mathrm{~m}$ (length $\times$ diameter), which is placed at the back of the enclosure (Table 1).

Figure 3 represents the distribution and the size of the obstacles inside the compartment for the Zig-Zag case. Whereas the compartment is 2,2 $\mathrm{m}$ wide, the parallelipedic obstacles are only $1.55 \mathrm{~m}$ wide and placed alternatively to the left then to the right of the room. The height of the obstacles has been chosen for its ability to cause a hydraulic jump in the progressing gravity current, see Table 2.

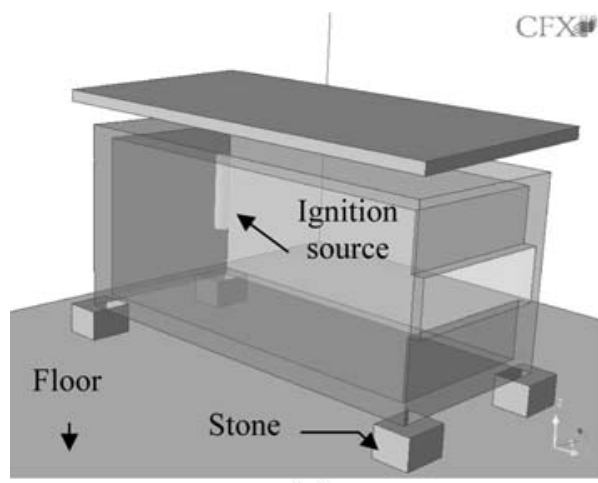

(a)

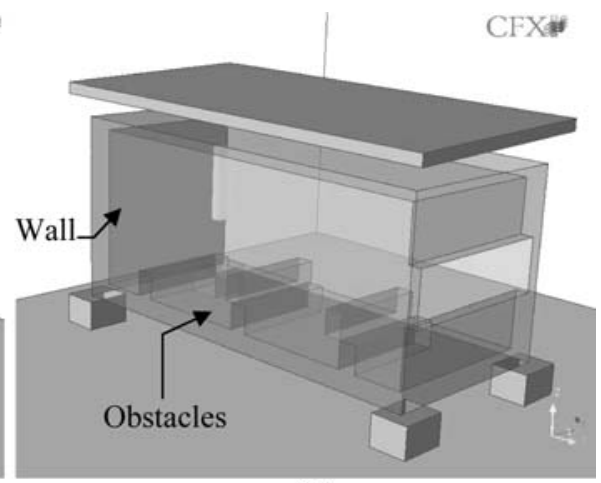

(b)

Figure 2. (a) Gravity current scenario without obstacles; (b) Gravity current scenario with obstacles. 


\section{Table 1 \\ Gas Composition Inside and Outside the Compartment at the Opening Time}

\begin{tabular}{lrllll}
\hline Mass fraction, $\Psi,(\%)$ & $\mathrm{CH}_{4}$ & $\mathrm{CO}_{2}$ & $\mathrm{H}_{2} \mathrm{O}$ & $\mathrm{N}_{2}$ & $\mathrm{O}_{2}$ \\
\hline Inside the compartment & 13.7 & 3.4 & 2.8 & 65.3 & 14.8 \\
Outside the compartment & 0.0 & 0.0 & 0.0 & 77 & 23 \\
\hline
\end{tabular}

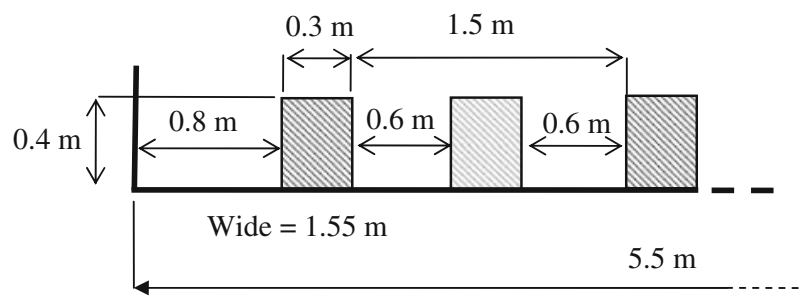

\section{Figure 3. Obstacles distribution in the compartment (Zig-Zag case).}

\subsection{Minimum Size of Obstacles that Cause Hydraulic Jump}

As mentioned before, obstacles create some flow resistance that may lead to breaking of the gravity wave and cause an internal hydraulic jump. Such jumps cause forced mixing that again will affect the resulting species concentrations and can alter the conditions for backdraft formation. If the compartment is longer than the $5.0 \mathrm{~m}$ of Gojkovic's experiments, friction from the floor may create a hydraulic jump in the same way as obstacles.

For obtaining the height of the obstacles that create hydraulic jump in the gravity current, it is first necessary to calculate the values of depth and velocity at the end of the inflow jet. Guigay et al. [6], describe how to obtain the velocity profile at the opening in detail. The buoyancy parameter $\beta$ [7] is used for that purpose.

In the next paragraphs, an algorithm for obtaining this is explained. The following equation, Equation (1), represents the densimetric form of the Bernoulli equation between the waterfall (w) and the upstream of the hydraulic jump (point 1). It can be solved using classical mathematical software. Only one of the roots for each density difference is valid for our problem. The results are given as $q, y_{\mathrm{w}}$ and $v_{\mathrm{w}}$ in Table 2. See also Figure 4.

$$
\begin{aligned}
& y_{\text {c.op }}+0.7+\frac{1}{2 \beta g} \frac{q^{2}}{y_{\mathrm{c}, \mathrm{op}}^{2}}=y_{\mathrm{w}}+\frac{1}{2 \beta g} \frac{q^{2}}{y_{\mathrm{w}}^{2}} \\
& y_{\mathrm{w}}^{3}-y_{\mathrm{w}}^{2}\left(0.7+y_{\mathrm{c}, \mathrm{op}}+\frac{1}{2 \beta g} \frac{q^{2}}{y_{\mathrm{c}, \mathrm{op}}^{2}}\right)+\frac{q^{2}}{2 \beta g}=0
\end{aligned}
$$

When a hydraulic jump is formed, corresponding depths of the cold airflow can be found. Considering a control volume (CV) right upstream of the flow (at 


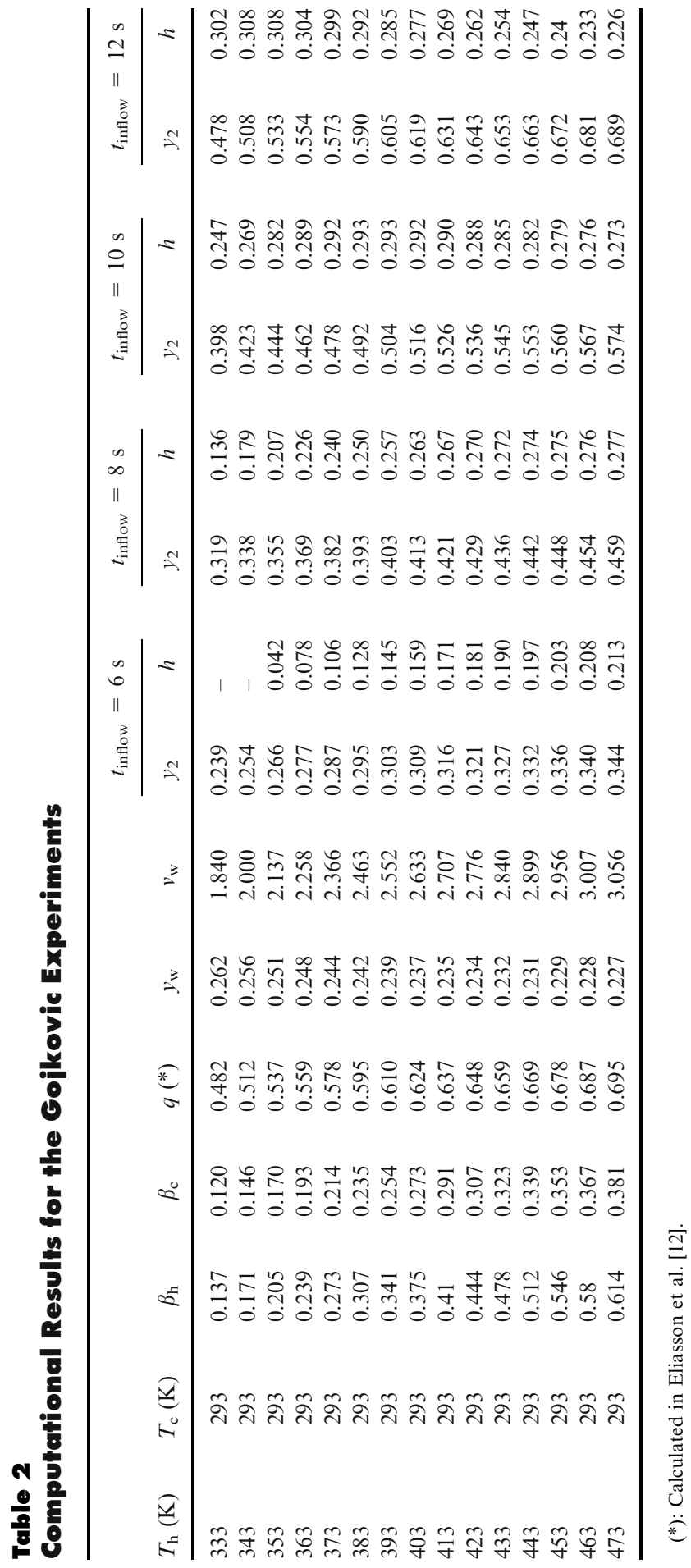




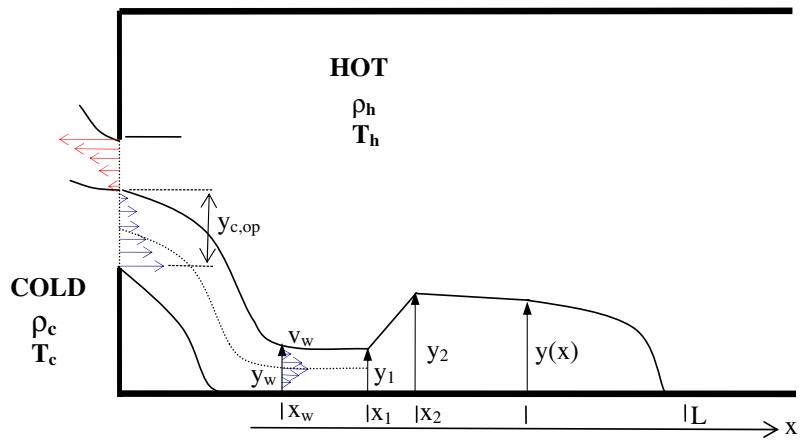

Figure 4. Layout of a gravity current entering in a compartment.

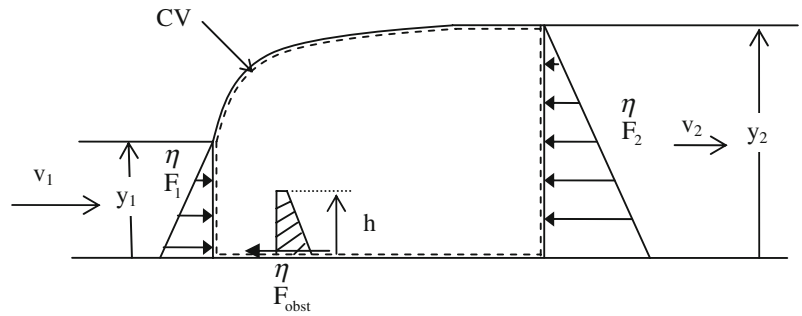

Figure 5. Control volume right upstream of the flow.

$\left.x=x_{1}\right)$ and downstream $\left(x=x_{2}\right)$ represented in Figure 5, the momentum equation can be written as:

$$
\sum_{\text {vol }} \vec{F}=\overrightarrow{F_{1}}+\overrightarrow{F_{2}}+\overrightarrow{F_{\text {obst }}}=0
$$

where $F_{\text {obst }}$ (force due to the obstacle) is defined in Equation (4).

$$
F_{\text {obst }}=C \frac{\rho v^{2}}{2} h
$$

The bottom friction forces are neglected, as the horizontal distance is very small. If $P_{1}$ and $P_{2}$ are the pressure upstream and downstream respectively, we have:

$$
\begin{aligned}
& \left\|\vec{F}_{1}\right\|=\int_{0}^{y_{1}} P_{1} \mathrm{~d} z=\int_{0}^{y_{1}}\left(\rho \beta g z+\rho v_{1}^{2}\right) \mathrm{d} z=\frac{1}{2} \rho \beta g y_{1}^{2}+\rho y_{1} v_{1}^{2} \\
& \left\|\vec{F}_{2}\right\|=\int_{0}^{y_{2}} P_{2} \mathrm{~d} z=\int_{0}^{y_{2}}\left(\rho \beta g z+\rho v_{2}^{2}\right) \mathrm{d} z=\frac{1}{2} \rho \beta g y_{2}^{2}+\rho y_{2} v_{2}^{2}
\end{aligned}
$$


With the direction of the forces, shown on Figure 2, Equation (3) can be written as:

$$
\begin{aligned}
& \frac{1}{2} \rho \beta g y_{1}^{2}+\rho y_{1} \frac{q^{2}}{y_{1}^{2}}-C \rho \frac{q^{2}}{y_{1}^{2}} h-\left[\frac{1}{2} \rho \beta g y_{2}^{2}+\rho y_{2} \frac{q^{2}}{y_{2}^{2}}\right]=0 \\
& y_{2}^{2}+\frac{2 q^{2}}{\beta g y_{2}}=y_{1}^{2}-C \frac{q^{2}}{\beta g y_{1}^{2}} h+\frac{2 q^{2}}{\beta g y_{1}}
\end{aligned}
$$

The height of obstacle will be:

$$
h=\frac{\beta g y_{1}^{2}}{C q^{2}}\left[y_{1}^{2}-y_{2}^{2}+\frac{2 q^{2}}{\beta g y_{1}}-\frac{2 q^{2}}{\beta g y_{2}}\right]
$$

This height of obstacle creates the necessary drag (thrust) to create a hydraulic jump. This condition is necessary, but not sufficient, as the flow may have specific energy high enough to override the obstacle without creating a jump.

We consider the height $h$ necessary to create a downstream wave of height $y_{2}$. The filling time $t$ needed to obtain this value $y_{2}$ is:

$$
t \approx \frac{q}{B L y_{2}}
$$

$B$ is the width of the container, and $L$ its length. Equation (10) presupposes that the baffles are placed as close to the inflow side as possible.

With the obstacle, the distance between $x_{\mathrm{w}}$ and $x_{1}$ is very small, so we can neglect friction between them. In this case we can then make the assumption that we have $y_{\mathrm{w}}=y_{1}$ and $v_{\mathrm{w}}=v_{1}$, in Figure 4 .

The values of the two dimensional flow rate $\mathrm{q}$ and the height of the cold layer at the opening $y_{\mathrm{c}, \mathrm{op}}$ depending on $\mathrm{c}$ are calculated in Guigay 2003. With these results, $y_{\mathrm{w}}$ is obtained from Equation (2) and $y_{2}$ from Equation (10) for different filling time.

It is estimated that baffles lower than the $6 \mathrm{~s}$ column will have very little effect. Baffles equal to the height in the $8 \mathrm{~s}$ will then be effective for $2 \mathrm{~s}$ of time, and baffles in the $12 \mathrm{~s}$. column effective for $6 \mathrm{~s}$. At that time two things happen, the flow will sail over the baffles and the $y_{2}$ depth will extend from wall to wall eliminating the hydraulic jump. The hydraulic jump with its increased mixing will thus be effective for very limited amount of time, 4-6 s. Nevertheless, this extra mixing may alter the flammability limits and thus change the risk of experiencing backdraft.

\subsection{Initial and Boundary Conditions}

The inner gas species accumulated inside the compartment at the opening time are methane $\left(\mathrm{CH}_{4}\right)$, carbon dioxide $\left(\mathrm{CO}_{2}\right)$, water vapour $\left(\mathrm{H}_{2} \mathrm{O}\right)$, nitrogen $\left(\mathrm{N}_{2}\right)$ and oxygen $\left(\mathrm{O}_{2}\right)$. Based on the concentration measured by Gojkovic [3], the initial mass 


\begin{tabular}{|c|c|c|}
\hline Part & Boundary type & Characteristics \\
\hline Floor & Wall & $\begin{array}{l}\text { Wall influence of floor: No slip } \\
\text { Wall roughness: Smooth wall } \\
\text { Constant temperature of } 278 \mathrm{~K}\end{array}$ \\
\hline Air & Opening & $\begin{array}{l}\text { Initial temperature of } 278 \mathrm{~K} \\
\text { Static pressure of } 1.0 \mathrm{~atm} \text { for outflow and } \\
\text { total pressure of } 1.0 \mathrm{~atm} \text { for the inflow }\end{array}$ \\
\hline Container obstacles & Wall & $\begin{array}{l}\text { Wall influence of floor: No slip } \\
\text { Wall roughness: Smooth wall } \\
\text { Initial temperature of } 310 \mathrm{~K}\end{array}$ \\
\hline
\end{tabular}

fraction of each gas has been calculated and summarized in Table 1. These values are applied in both simulations, the Zig-Zag case and the Free-obstacle case.

The initial velocity inside and outside the enclosure is taken as zero. The average initial temperature of the gas inside the compartment, $T_{\mathrm{h}}$, and the gas outside the compartment, $T_{\mathrm{c}}$, is 310 and $278 \mathrm{~K}$, respectively. This gives a buoyancy parameter, Equation (11), of 0.2.

$$
\beta=\frac{\left(\rho_{\mathrm{h}}-\rho_{\mathrm{c}}\right)}{\rho_{\mathrm{h}}}=1-\frac{T_{\mathrm{c}}}{T_{\mathrm{h}}}
$$

In the numerical simulations performed, the Detached Eddy Simulation (DES) turbulence model was used [8]. The initial turbulence kinetic energy $k$ and eddy dissipation $\varepsilon$ were set to 0.0001 and $0.0001 \mathrm{~m}^{2} / \mathrm{s}^{3}$, respectively.

The boundary conditions for the container walls, obstacles, floor and the surrounding ambient are summarized in Table 3.

\section{Results of Simulation}

\subsection{Main Parameters}

Four parameters are examined from the simulations: the transit time $\left(t_{\text {trans }}\right)$, the gravity current velocity $\left(v_{\mathrm{gc}}\right)$, the Froude number $(\mathrm{Fr})$ and the ignition time $\left(t_{\text {ignition }}\right)$.

The transit time is a parameter used by Fleischmann [1] in his scaled saltwater experiments. It represents the time required for the leading edge of the gravity current to reach the wall opposite the opening. In the performed numerical simulations, a change of the mass fraction of $10 \%$ at the rear wall was used as a criterion.

Then, knowing the transit time and the distance between the opening wall and the end wall, $L$, the average gravity current velocity can be obtained using Equation (12).

$$
v_{\mathrm{gc}}=\frac{L}{t_{\text {trans }}}
$$


The Froude number, is calculated in terms of the gravity current velocity, the buoyancy parameter, $\beta$, and the height of the compartment, $h$, using Equation (13).

$$
\operatorname{Fr}=\frac{v_{\mathrm{gc}}}{\sqrt{\beta g h}}
$$

The ignition time can be defined as the time interval between the opening of the compartment hatch and the instant in which the gravity current reaches the ignition source (electric wire) and dilutes the mixture of hot gases to its flammability limits.

In the simulations, the methane volume fraction is checked in the small cylindrical volume at the back of the enclosure in each time step. If the methane volume fraction is locally inside its flammability limits $[5,13]$, the ignition is supposed to take place. As the aim of this paper is to show the influence of the obstacles on the gravity current, the deflagration of the combustible mixture after ignition was not simulated.

The numerical simulations were performed using CFX 5.7.1 code. The first $30 \mathrm{~s}$ of the flow were simulated with a time step of $0.02 \mathrm{~s}$. The total number of elements (tetrahedrons) was around 500,000 for each simulation. The computer used for the simulation was Pentium(R) $4 \mathrm{CPU} 2.40 \mathrm{GHz}, 512 \mathrm{Mb}$ RAM.

\subsection{Visual Comparison of the Results: Zig-Zag Case vs. Free-Obstacles Case}

From the simulation, instantaneous fields of velocity and mass fractions of methane were obtained. Figure 6 shows methane mass fraction for the gravity current vertical cross-section in the Free-obstacles case at time $4.2 \mathrm{~s}$.

Figure 7 presents methane mass fraction for the Zig-Zag case also at time $4.2 \mathrm{~s}$. The hydraulic jump and vortex created by the obstacles is clearly seen. Higher vortexes are obtained in the Zig-Zag case than in the Free-obstacles case.

Figures 8 and 9 represents the fields of mass fraction of methane for both cases at 10.2 and $19.2 \mathrm{~s}$, respectively. A direct comparison of these scenarios is possible. One can say that the obstacles considered here create more local mixing and turbulence but not necessarily a well-mixed situation throughout the compartment. One may well observe a higher average gravity current velocity when obstacles are not present.

\subsection{Quantitative Comparison of the Results: Zig-Zag Case vs. Free-Obstacles Case}

The ignition time, the gravity current velocity, the transit time and Froude number for both simulations are given in Table 4. Column 1 indicates the type of scenario, column 2 shows the transit time, $t_{\text {trans, }}$, column 3 gives the average gravity current velocity, $v_{\mathrm{gc}}$, column 4 gives Froude number and column 5 and 6 give the ignition time computed in simulations, $t_{\text {ignition, and the ignition time obtained }}$ from the backdraft experiments, $t_{\text {ignition experimental }}$. 


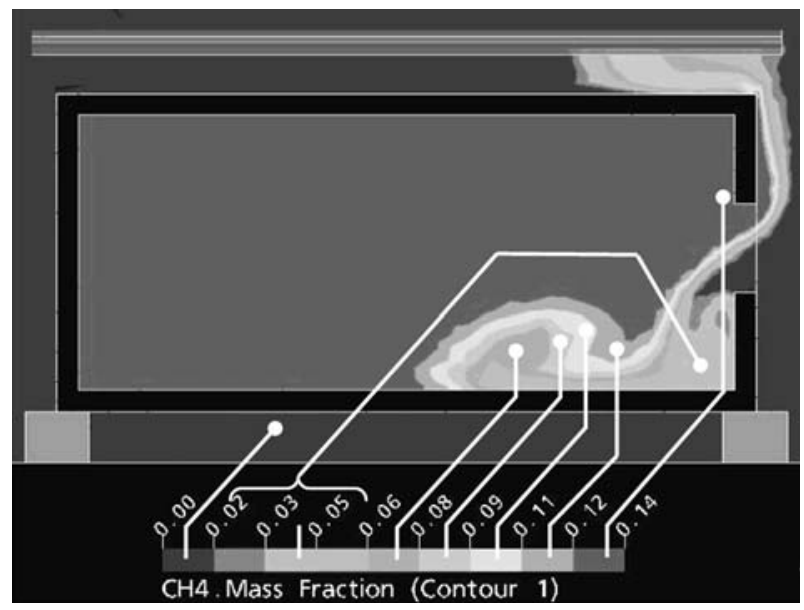

Figure 6. (a) Mass fraction of methane of the gravity current for the Free-obstacles case at time $\mathbf{4 . 2} \mathrm{s}$.

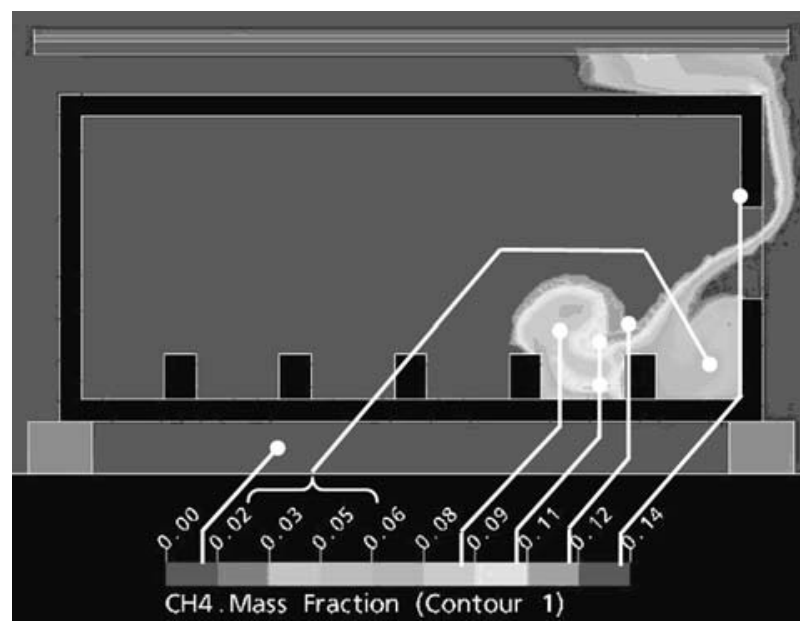

Figure 7. (a) Temperature of the gravity current of the Zig-Zag case at time $\mathbf{4 . 2} \mathrm{s}$.

Based on the results, it can be observed that the average velocity of the gravity current in Zig-Zag case is reduced in comparison with the Free-Obstacles case. For this compartment ratio and obstacle size and distribution, the gravity current velocity is divided by a factor of 2 when including obstacles.

The influence on the level of mixture can be also observed in the value of the ignition time computed for the Zig-Zag and Free-Obstacles cases, see Table 4. The time at which a flammable region of the gravity current reaches the ignition wire when including obstacles is 0.54 of the free-obstacle case. 


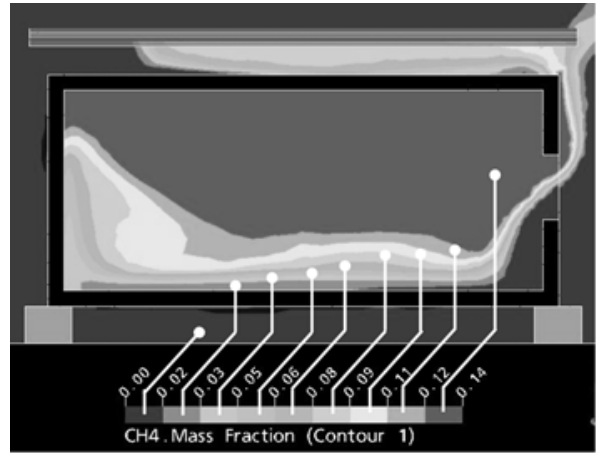

(a)

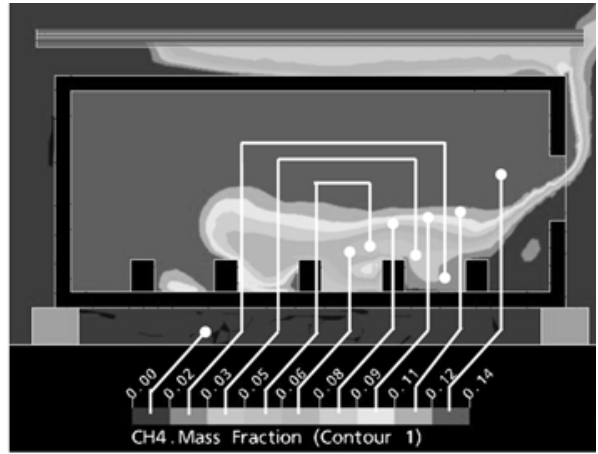

(b)

Figure 8. Fields of mass fraction of methane at $10.2 \mathrm{~s}$ from the opening time: (a) Free-obstacles case; (b) Zig-Zag case.

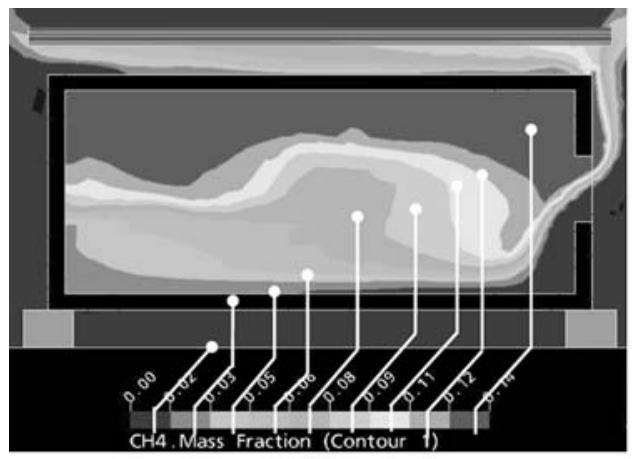

(a)

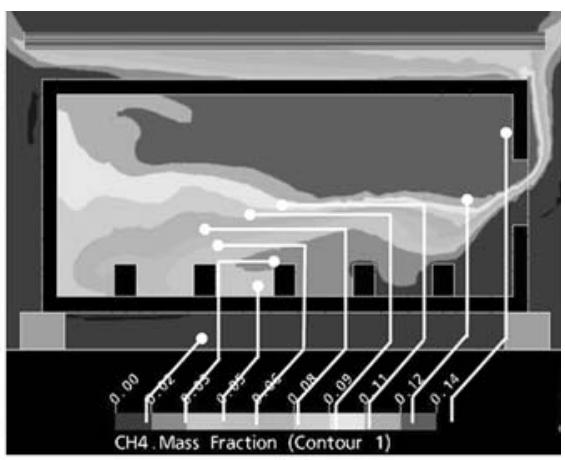

(b)

Figure 9. Fields of mass fraction of methane at $19.2 \mathrm{~s}$ from the opening time: (a) Free-obstacles case; (b) Zig-Zag case.

\begin{tabular}{|c|c|c|c|c|c|}
\hline & $t_{\text {trans }}$ & $V_{\mathrm{gc}}$ & $\mathrm{Fr}$ & $t_{\text {ignition computed }}$ & $t_{\text {ignition experimental }}$ \\
\hline Free-obstacles case & 8.4 & 0.65 & 0.31 & 13.5 & Min: 15 Max: 45 \\
\hline Zig-Zag case & 14.2 & 0.32 & 0.18 & 24.9 & - \\
\hline
\end{tabular}

One may also observe a great decrease in the Froude number in the Zig-Zag case. According to Benjamin [9], the Froude number for flows without mixing between fluids (no energy losses) is equal to 0.5. Thus, lower values of the Froude number should be interpreted as higher level of mixing between fluids and therefore, as a lower average gravity current velocity. 
Comparing the ignition time of the Free-obstacles case with the ignition time of Gojkovic's experiment, a lower value is obtained in the simulation. Better results could be found if instead of having considered a uniform gas temperature distribution inside the compartment at the initial time, a stratified temperature distribution would be chosen.

\subsection{Conclusions}

Numerical analysis of gravity current behaviour in a compartment with and without obstacles (Zig-Zag and Free-Obstacles case) was performed using CFX 5.7.1 code. The conditions from the experiment No. 9 [3] were used for the initial and boundary conditions in the numerical models.

Thus, the scaled saltwater experiments carried out by Fleischmann [1] have been used for validating the accuracy of the setup of the model. Also the Free-obstacle case is used for validating the accuracy of the setup of the model such as boundary conditions, inner gas concentration with Gojkovic's experiments and also for comparing the influence of the obstacles with the Zig-Zag case.

The obstacles height has been chosen in such a way that a hydraulic jump is created in the gravity current. It shows that having obstacles in a compartment can alter significantly the gravity current structure, level of mixing and average gravity current velocity and therefore it can affect the severity and intensity of a backdraft deflagration.

Based on the results, it is observed that the ignition time and the transit time are multiply by a factor close to 2 and the Froude number divide by 2 for the Zig-Zag case. These factors will change as a function of the obstacles distribution. Other obstacle distribution have been analysed in [10].

The delay in the ignition time caused by obstacles can mislead the fire fighters that face a fire in a compartment with a high density of obstacles. The risk of backdraft may indeed persist for a longer duration in such a case than what has been experienced in previous fires with few obstacles, or in experimental, demonstration or practice backdrafts that are usually performed in the total absence of obstacles.

Further research should be focused on gravity currents in more complex enclosures with different obstacles distribution (e.g. typical furniture or equipment distribution in real compartments) and openings. Also the study of gravity currents in enclosures in which hot items are still present on the floor when the gravity current enters the enclosure should be studied, because the local energy dissipation and the associated buoyancy current may also disturb the gravity current. This would help to elucidate, in a more realistic way, the gravity current's structure.

\section{Acknowledgements}

The present work was performed as a part of the project "Under-Ventilated Compartments Fires (FIRENET)" (Co. No. HPRN-CT-2002-00197) led by Prof. J. Wen, Kingston University. The project is supported by the EU Research Training Network FP5, which is gratefully acknowledged. 


\section{Annex}

\section{Experimental Setup of Fleischmann's Experiments}

The saltwater experiments were conducted by placing an acrylic compartment within a larger glass tank. The tank $(0.3 \mathrm{~m}$ wide, $0.6 \mathrm{~m}$ long, and $0.45 \mathrm{~m}$ deep) contained a dense saline solution ranging in density from 1.003 to $1.101 \mathrm{~kg} / \mathrm{m}^{3}$. The solution temperature was $18^{\circ} \mathrm{C}$. Standard rock salt crystals were dissolved in tap water to raise the density to the desired level.

The compartment was constructed using $6.0 \mathrm{~mm}$ thick acrylic with an interior dimension of $0.15 \mathrm{~m}$ wide, $0.3 \mathrm{~m}$ long and $0.15 \mathrm{~m}$ high. The openings were a fully opened wall $(0.15 \mathrm{~m} \times 0.15 \mathrm{~m})$, a horizontal slot $(0.15 \mathrm{~m}$ wide $\times 0.05 \mathrm{~m}$ high $)$

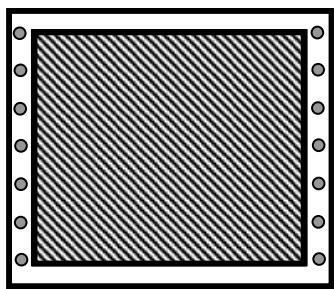

Full

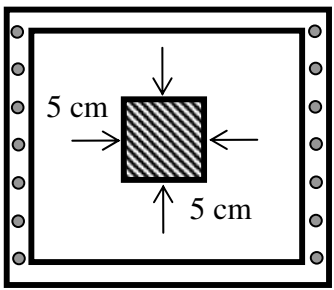

Centred Window

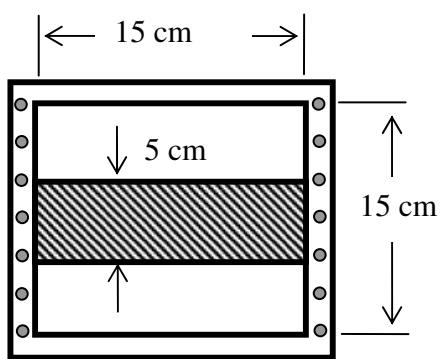

Middle-slot

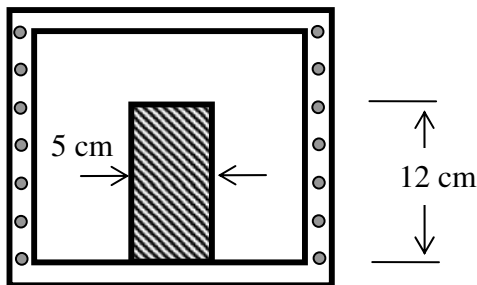

Centred Door

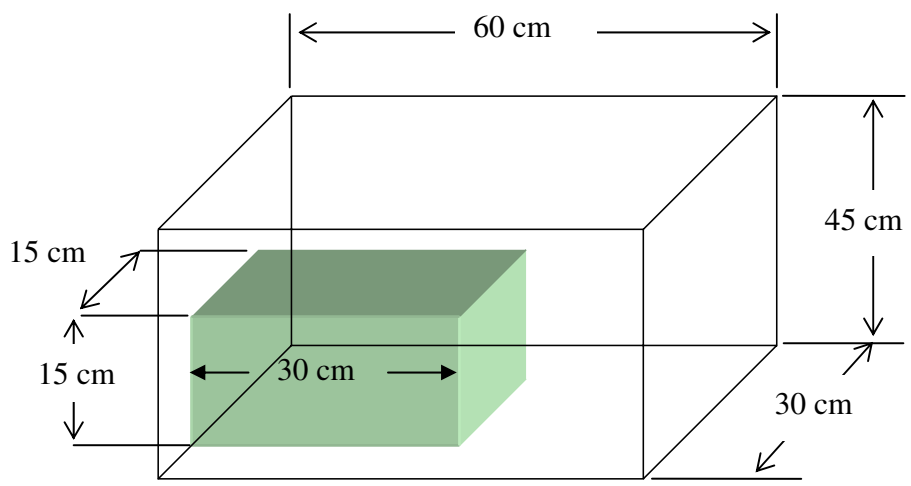

Figure 10. Saltwater configuration and opening geometries used in Fleischmann's experiments. 
centred vertically at the end of the wall, a window $\left(0.05 \mathrm{~m}^{2}\right)$ centred vertically and horizontally on the wall and the last opening was a door $(0.12 \mathrm{~m}$ high $\times 0.05 \mathrm{~m}$ wide) centred horizontally with the bottom of the opening at floor level. Figure 10 shows the saltwater configuration and the opening geometries.

\section{Initial and Boundary Conditions}

In each of these simulations the fluid used is air. To obtain the difference in density between the inner and outer air, different temperatures are given. In the saltwater experiment, the temperature of both fluids remains constant $\left(18^{\circ} \mathrm{C}\right)$ and the difference in density is obtained by adding more or less salt. This difference between the simulation and the physical model has no influence on the results.

The dimensions of the compartment are identical to the experimental setup. The compartment is positioned on the far left of the saltwater container, which is $0.55 \mathrm{~m}$ long, $0.35 \mathrm{~m}$ deep and $0.3 \mathrm{~m}$ wide. The enclosure is also raised $5.0 \mathrm{~cm}$ from the bottom of the container (Figure 10).

The density of the inner and the outer fluid is 1.205 and $0.833 \mathrm{~kg} / \mathrm{m}^{3}$, respectively. These values are obtained by giving an initial temperature of 423 and $293 \mathrm{~K}$ for the inner and outer fluid, respectively, which gives a buoyancy of 0.3072 . Only one value of buoyancy is simulated for each opening geometry since the Froude number values are independent of the density difference ratio [1].

To simulate these scenarios, the $k$-epsilon turbulent model has been used, with an initial $\mathrm{k}$ and epsilon equal to $0.0001 \mathrm{~m}^{2} / \mathrm{s}^{2}$ and $0.0001 \mathrm{~m}^{2} / \mathrm{s}^{3}$, respectively. The velocity inside and outside the enclosure was initially set to 0.0 . The inner fluid mass fraction was set to 1.0 inside the compartment and 0.0 outside the compartment. For the outer fluid the opposite values are given, i.e. 0.0 inside the compartment and 1.0 outside the compartment. The boundary conditions for the container, floor and air are summarized in Table 5.

About $20 \mathrm{~s}$ were simulated with a time step of $0.02 \mathrm{~s}$. The total number of elements (tetrahedrons) for each simulation is around 400,000.

\begin{tabular}{|c|c|c|}
\hline Part of scenario & Boundary type & Characteristics \\
\hline Floor & Wall & $\begin{array}{l}\text { Wall influence on floor: No slip } \\
\text { Wall roughness: Smooth wall } \\
\text { Heat transfer: Adiabatic }\end{array}$ \\
\hline Air & Opening & $\begin{array}{l}\text { Initial temperature: } 293 \mathrm{~K} \\
\text { Floor direction: Normal to boundary conditions }\end{array}$ \\
\hline Container & Wall & $\begin{array}{l}\text { Wall influence on floor: No slip } \\
\text { Wall roughness: Smooth wall } \\
\text { Heat transfer: Adiabatic }\end{array}$ \\
\hline
\end{tabular}




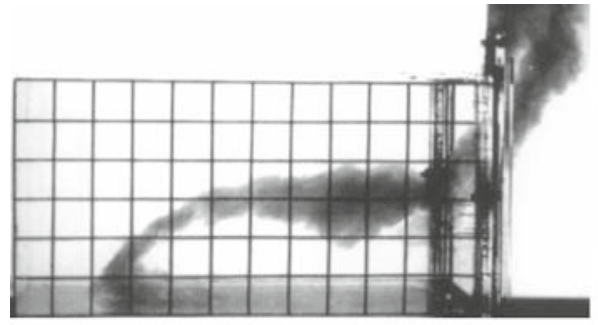

Photograph of the gravity current approximately $3 \mathrm{~L} / 4$ into the compartment for the fully open condition

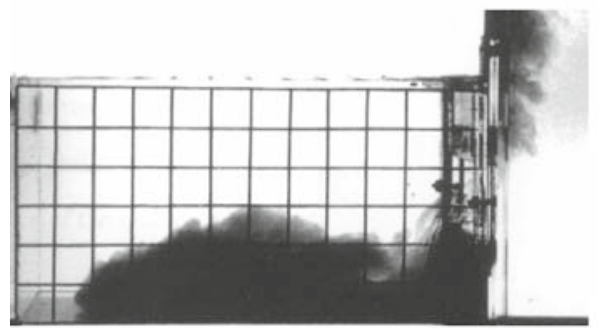

Photograph of the gravity current approximately $3 \mathrm{~L} / 4$ into the compartment for the middle-slot opening condition

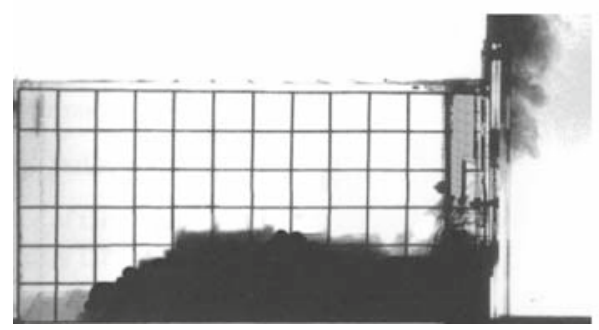

Photograph of the gravity current approximately $3 \mathrm{~L} / 4$ into the compartment for the centred window condition

(a)

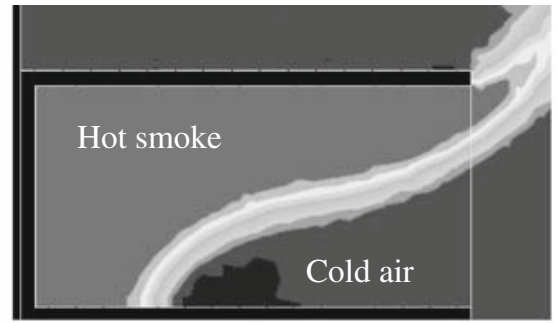

Mass fraction profile for the full opening case of the gravity current approximately $3 \mathrm{~L} / 4$ into the compartment

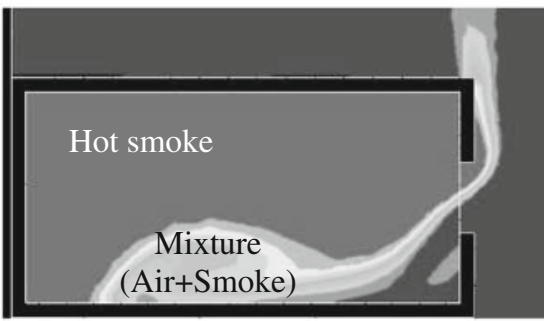

Mass fraction profile for the middleslot opening case of the gravity current approximately $3 \mathrm{~L} / 4$ into the compartment

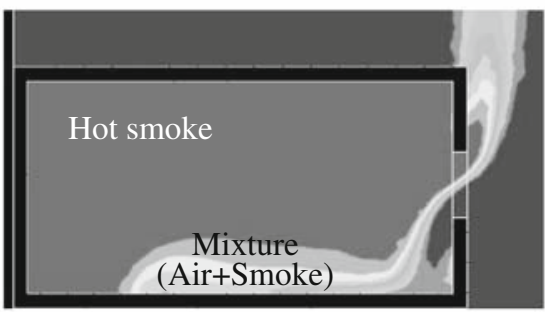

Mass fraction profile for the centred window opening case of the gravity current approximately $3 \mathrm{~L} / 4$ into the compartment

(b)

Figure 11. Visual comparison between (a) saltwater experiments and (b) CFX simulation. 


\section{Qualitative Comparison of the Results: Scaled Saltwater Experiments vs. Simulations}

Figure 11(a) represents photographs taken from the saltwater experiments. They represent the mass fraction of the gravity current approximately $3 L / 4$ into the compartment for different opening geometries. Black represents the inner fluid and the lightest colour is for the outer one.

These photographs closely resemble the numerical simulation results shown in Figure 11(b).

\section{Quantitative Comparison of the Results: Scaled Saltwater Experiments vs.}

\section{Simulations}

To compare the numerical simulations quantitatively with the experiments, the non-dimensional velocity or Froude number and the transit time, $t_{\text {trans }}$, is used.

For the saltwater experiments, the transit time was taken from a video recording of the gravity current. Once the gravity current reaches the rear wall, it is reflected up and around until it travels toward the opening. A Froude number is also calculated for the returning current. The returning gravity current is defined in Equation (14), where $t_{\text {out }}$ is the time from opening to the time the reversed current returns to the opening wall.

$$
v_{\mathrm{gc}}=\frac{2 \cdot L+2 h_{1} / 3}{t_{\mathrm{out}}}
$$

The $2 h_{1} / 3$ factor is used to account for the length the current must travel up the wall opposite the opening [1].

\section{Results of the Simulation}

Table 6 shows $t_{\text {trans }}, t_{\text {out, }}$ and the buoyancy parameter $\beta$ obtained from simulations as well as a comparison between the Froude numbers (entering and exiting) from saltwater experiments and simulations.

Table 7 represents $h_{0}$ obtained from simulation and the average value of $h^{*}$ obtained by simulations and experiments. Note that $h_{\mathrm{o}}$ is height of the gravity

\section{Table 6}

\section{Bouyancy Parameter, $t_{\text {trans, }} t_{\text {outr }}$ and Froude Number from Saltwater Experiments and CFX Simulation for Different Opening Geometries}

\begin{tabular}{|c|c|c|c|c|c|c|c|}
\hline \multirow[b]{2}{*}{ Case } & \multirow[b]{2}{*}{$B(-)$} & \multicolumn{3}{|c|}{ Entering current } & \multicolumn{3}{|c|}{ Exiting current } \\
\hline & & $\mathrm{CFX} t_{\text {trans }}(\mathrm{s})$ & Fr exper. & Fr CFX & $\mathrm{CFX} t_{\text {out }}(\mathrm{s})$ & Fr exper. & Fr. CFX \\
\hline Full opening & 0.3072 & 0.99 & 0.44 & 0.45 & 2.3 & - & 0.45 \\
\hline Slot opening & & 1.35 & 0.32 & 0.33 & 3.2 & 0.32 & 0.32 \\
\hline Centred door & & 1.20 & 0.35 & 0.37 & 2.9 & 0.35 & 0.36 \\
\hline Centred window & & 2.00 & 0.22 & 0.22 & 5.1 & 0.22 & 0.20 \\
\hline
\end{tabular}




\section{Table 7}

Comparison of $h_{0}$ and $h^{*}$ : Simulation vs. Experiments

\begin{tabular}{lccc}
\hline & $h_{\mathrm{o}}($ simulated $)(\mathrm{cm})$ & $h^{*}($ simulated $)$ & $h^{*}($ exp. $)$ \\
\hline Full opening & 7.5 & 0.50 & 0.50 \\
Slot opening & 5.8 & 0.38 & 0.38 \\
Door opening & 4.8 & 0.32 & 0.33 \\
Window opening & 4.1 & 0.27 & 0.29 \\
\hline
\end{tabular}

current measured over the distance $3 L / 4$ to $L$. This interval is chosen to reduce any effects caused by the openings, $h^{*}$ is defined as $h_{\mathrm{o}} / h_{1}$.

The simulations and the experiments were found to agree. As a result, one may now say that the setup of the model has been well defined. One may then well suppose that the simulations carried out in the following sections will lead to the same accurate results.

\section{References}

1. Fleischmann CM (1993) Backdraft phenomena, NIST-GCR-94-646. University of California, Berkeley

2. Weng WG, Fan WC, Yang LZ (2002) Study on Salt water modelling of gravity currents prior to backdrafts using flow visualization and digital particle image velocimetry. Exp Fluids 33:398-404

3. Gojkovic D (2000) Initial backdraft experiments. Department of Fire Safety Engineering, Lunds Tekniska Högskola Universitet, Report 3121

4. Horvat A, Sinai Y, Gojkovic D, Karlsson B (2008) Numerical and experimental investigation of backdraft. Combust Sci Technol 180(1):45-63

5. Drysdale D (1990) An introduction to fire dynamics, John Wiley \& Sons, Chichester, UK

6. Guigay G, Elíasson J, Horvat A, Sinai Y, Karlsson B (2008) Semi-analytic and CFD calculation of gravity flows in backdraft studies. J Fire Sci. doi:10.1007/s10694008-0058-4

7. Pedersen FB (1986) Environmental hydraulics: stratified flows. Springer Verlag

8. Menter FR, Kuntz M (2003) Development and Application of a Zonal DES Turbulence Model for CFX-5. CFX-Validation Rep CFX-VA L17(0503)

9. Benjamin TB (1968) Gravity current and related phenomena. J Fluid Mech 31:209-248. doi: $10.1017 /$ S0022112068000133

10. Pérez Jiménez C (2006) Simple numerical model for backdraft risk assessment. Thesis at the University of Liege, Belgium

11. Pérez-Jiménez C (2004) Simple numerical model for backdraft risk assessment. In: 1st International PhD Workshop of Fire safety Science and Engineering. Hannover

12. Elíasson J, Guigay G, Karlsson B (2008) Enclosure fires, gravity currents and the backdraft problem. J Fire Sci. doi:10.1177/0734904108092116, JFS 092116 (in press)

13. Nederlandse Gasunie NV (1998) Physical Properties of Natural Gases, Groningen, Netherlands

14. Fleischmann CM, McGrattan KB (1999) Numerical and experimental gravity currents related to backdrafts. Fire Safety J 33:21-34 